\title{
Reconstructing Qatari Heritage: Simulacra and Simulation
}

\author{
Mariam Ibrahim Al-mulla \\ Qatar University, Doha, Qatar
}

\begin{abstract}
Qatar today focuses so much on reconstructing its cultural heritage. It is clear that the reconstruction of Qatari heritage has stemmed from a nostalgic mood. Thus, the government subsumed that heritage into certain interpretations and readings. Therefore, as presented today, Qatari heritage is no longer a self-referential heritage of an indigenous culture. Rather, it has become a principle to reflect the social and economic existence of the Qatari community along with other global communities. The mass use of heritage and the implementation of Western museum culture, however, might be viewed by some as the importation of a culture rather than the preservation of an existing one. To minimise such potential problem, the government opted to ignore any distinctions between representing heritage, interpreting it, or imposing new ideas and thinking around it. Instead, it has focused on introducing a heritage based on linking images of foreign elements that characterise Qatari heritage with new social and economic experiences.
\end{abstract}

Keywords: Qatari heritage, Souk Waqif, Qatari architecture, Qatari traditions, cultural heritage in Qatar, Museum of Islamic Art

\section{Introduction}

This paper raises an essential question, which is why Qatar is putting the wealth generated in the last 40 years from its oil and natural gas reserves into the creation and concentration in cultural heritage that aims to reorder its cultural codes. Therefore, I am suggesting within my investigation the need to consider what lies between the use of the ordering codes and the order itself. I will attempt to show why and in what ways the Qatari government has manifested the existence of an "order", how far that order has the ability to impose changes on society, and how the order has been applied to link space and time and represent values that create a certain knowledge, philosophy and narrative. Such an analysis aims to discover on what basis and within what limits the construction of knowledge, narrative and theory through the construction of a heritage became possible. I highlight which and whose history has been envisaged and which experiences have been reflected, which ideas have been used, and which rational values have been referred to in order to create a new heritage model.

\section{Reclaiming Heritage: Representation of an Absent Heritage}

If Qatar has achieved its economic peak in the oil industry in recent years, it has also learnt not to rely solely on this achievement, as peaks are likely to be followed by a fall. Therefore, such historical lessons have forced Qatar to think about investment in culture and human resources through focusing in enhancing and

Mariam Ibrahim Al-mulla, Ph.D., Assistance Professor, Humanities Department, College of Arts and Sciences, Qatar University. 
highlighting its heritage as well as the establishment of different specialist museums. This is one reason why Qatar today focuses so much on reconstructing its cultural heritage. The mass use of heritage and the implementation of Western museum culture, however, might be viewed by some as the importation of a culture rather than the preservation of an existing one. Aware of this potential problem, the government's response has been to ignore any distinction between representing heritage, interpreting it, or imposing new ideas and thinking around it. Instead, it has focused on introducing a heritage based on linking images of foreign elements that characterise Qatari heritage with new social and economic experiences.

It is clear that the reconstruction of Qatari heritage has stemmed from a nostalgic mood. This nostalgia for the past is a fiction that represents an absent heritage and an imagined reality, which, in its turn, undermines any comparison to real heritage. Therefore, as presented today, Qatari heritage is no longer a self-referential heritage of an indigenous culture. Rather, it has become a principle to reflect the social and economic existence of the Qatari community along with other global communities “in the era of high-tech capitalism” (Baudrillard, 1981, p. 6). It is a vantage point, a reflection of power, wealth and change. It is no longer itself; it is a simulated heritage that wishes to present Qatar's privileged position on the world map. This is why, throughout my paper, I undertook a careful reading of Qatari heritage to see if I could reconcile what has been simulated and created today with what might be called an indigenous heritage. The government is using heritage (as they see it) as a reflection and production of historical facts and as an instrument; yet, the government has buried itself within it, in the hope of finding a sense of reality in sites that could become representative of Qatari history.

Thus, this paper is not about heritage and culture perse: it is about the way that the government has imposed meaning upon that culture and heritage. It is about the way that the government subsumed that heritage into certain interpretations and readings. To understand the current mood for nostalgia and heritage, it is essential to reflect upon Qatar during the reign of Sheikh Hamad bin Khalifa (1995-present). Souk Waqif is a perfect example of how during his reign Qatari heritage has been manipulated by the government. A reading of the restoration/recreation of Souk Waqif demonstrates that the simulation of the Souk is not about history or heritage; rather, it is a fiction simulated via the way that the government has interpreted that history and heritage.

\section{Qatar During the Reign of Sheikh Hamad Bin Khalifa}

Such a rereading became vital as a result of the Sheikh's acknowledgement that his predecessor's failure to develop the country was a major part of his downfall. During the reign of the previous Emir, traditional Qatari architecture had been subjected to compulsory demolition, in order to build new cities and sites. There were a very small number of exceptions in the 1970s and 1980s when traditional Qatari architecture was preserved in museums. In the Arabian Gulf countries generally, there has been a loss of traditional architecture through demolition to make way for development in construction and civil engineering plans. The former development needs of Arabian Gulf countries have since raised questions about whether or not we could have saved examples of traditional architecture during the development process and, if so, how could we have saved them? In his study The Problems of Preserving Architecture in the Urban Area in Sharja (1995), Graham Anderson says that unfortunately these low adobe buildings, which occupied a great area of land, sometimes in the centre of cities, were seen as obstacles in the development process of the Arabian Gulf region. Added to that, the lack of awareness among the communities of the value and worth of this architectural inheritance facilitated the government's demolition plans. If these buildings had been modified for reuse, they could have 
enhanced and enriched the civic inheritance without preventing modernisation. However, the owners of these properties were influenced by the compensation they were offered for their destruction. Whole towns were abandoned, with many treasures of traditional architecture demolished. These buildings were replaced by new ones such as that in Figure 1, a government building housing the Public Authority for Youth and Sport. In adopting a bland Western architectural style, this building (and others like it) did not refer to native Qatari culture or heritage. It may have been viewed by the government of the time that adopting Western style was a way of keeping up with international developments. Such modern buildings were seen as indicative of the state’s modernity.

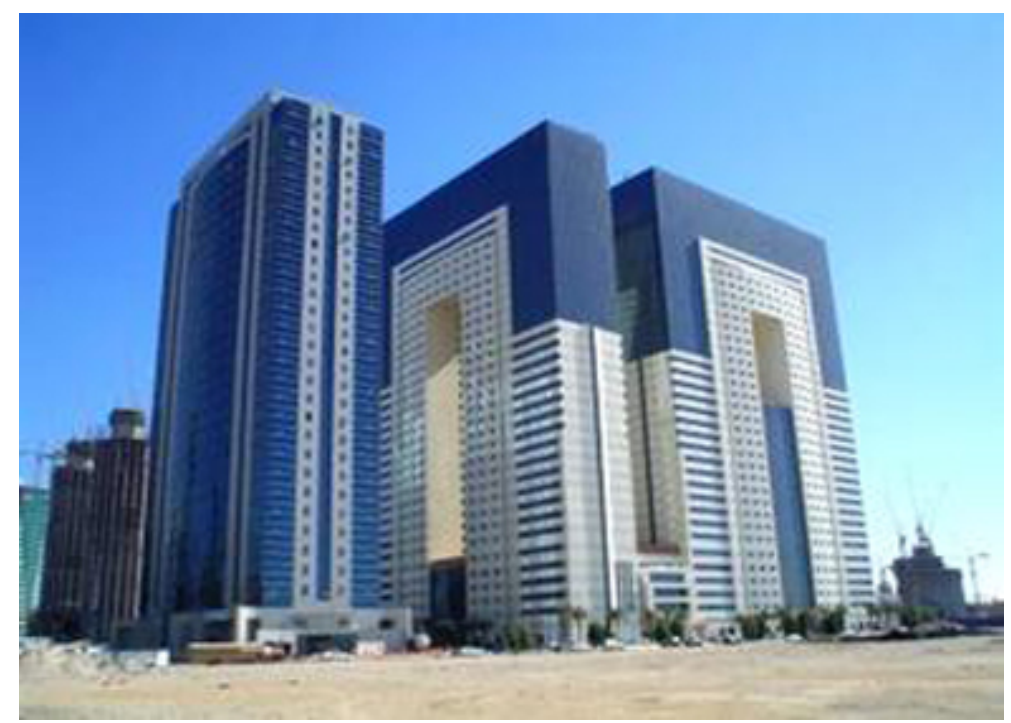

Figure 1. The Public Authority for Youth and Sport building, Doha, built in the 1990s.

Perhaps Sheikh Hamad decided that even if funding were provided to protect and preserve the national inheritance of architecture, it still would not prevent the influence of human nature, which had hindered preservation in the past and encouraged its destruction. Something different needed to be done and Sheikh Hamad provided a glimmer of hope for this cultural inheritance in his development plans. His attempts to modernise the state meant balancing demands for new office buildings, trade headquarters, ministry buildings and vertical residential buildings that befitted a geographically small country's enlargement with the need to protect the irreplaceable national architectural inheritance. This is why he began his preservation plans with Souk Waqif, the traditional Qatari market, which had been restored in a modern style quite different from traditional Qatari architecture during the reign of his predecessor, Sheikh Khalifa.

Developments in awareness of the past and the practice of representing it mark a key difference between the previous political system and the present one. When the previous Emir made his development plans, he might have considered preserving Qatari traditions, such as ethnographic materials, in the national museum. However, the need to preserve Qatari architecture was lost in the need to develop the civic infrastructure of the country, which resulted in the construction of new buildings in styles imported from the West. Kevin Walsh says that society has what he refers to as "the organic past":

[...] Something which was present in construction of the sense of place. This may be considered as a more organic form of history, one which recognised the crucial contingency of past processes on present places. Places, natural and human-made features, acted as "time-makers", physical phenomena which exist in the present but possess, for those who 
know them, a temporal depth which gives them a special meaning. An important form of such a time-maker is the boundary, the perceived periphery of a community’s locality. (Walsh, 1992, pp. 11-12)

The experience of development and urbanisation in the 1980s and early 1990s destroyed many aspects of Qatar's organic past. Politicians today believe that “the sense of the past developed by the new urban mass' is an important element that has to be considered. As such, there has been a drive to recreate the places that reflect this organic past. In seeking “the ever more modern world” (Walsh, 1992, p. 12), the Qatari experience prior to 1995 witnessed a move towards a concept of itself that was dominated by the new.

\section{Restoration of Souk Waqif: Nostalgic Mood \& the Relationship Between Heritage and Identity}

In 2004, having seen how the historical souk lost its original character through the replacement of its modest architecture of adobe and timber with cement, iron windows and doors, and the installation of air conditioning, Sheikh Hamad commissioned a private architectural engineering consultancy from the Emiri Diwan to undertake reconstruction work. ${ }^{1}$ The intention was to restore the buildings of Souk Waqif to something like their traditional appearance (Figures 2-4). These restoration plans were drawn up after consulting old cartograms and manuscripts and old aerial photographs taken in the 1950s and 1960s. This was supplemented by the testimony of a group of elderly people who could recall its original appearance.

The Al-Arab newspaper reported that:

The restoration work the site has undergone is aimed at preserving the heritage of the place, especially after its being the most-favoured site for UNESCO as representative of Qatari architecture. Restoring the Souk in its original form was an inevitable requirement. (Behaper, 2008)

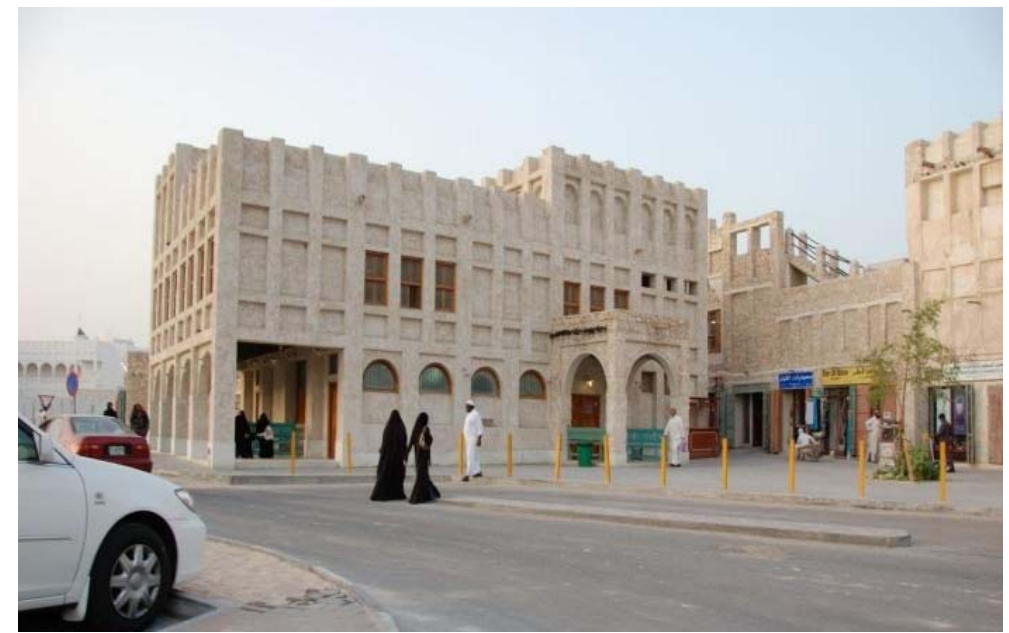

Figure 2. Souk Waqif after restoration/reconstruction in 2004-2005 using old building materials such as adobe walls and timber doors and window frames, photographed in 2009.

\footnotetext{
1 The Emiri Diwan is a royal centre from where the state is governed. All governmental offices that belong to the Emir's office are situated there. The Emir also receives his formal guests, such as heads of state or their representatives or local people, at the Emiri Diwan.
} 


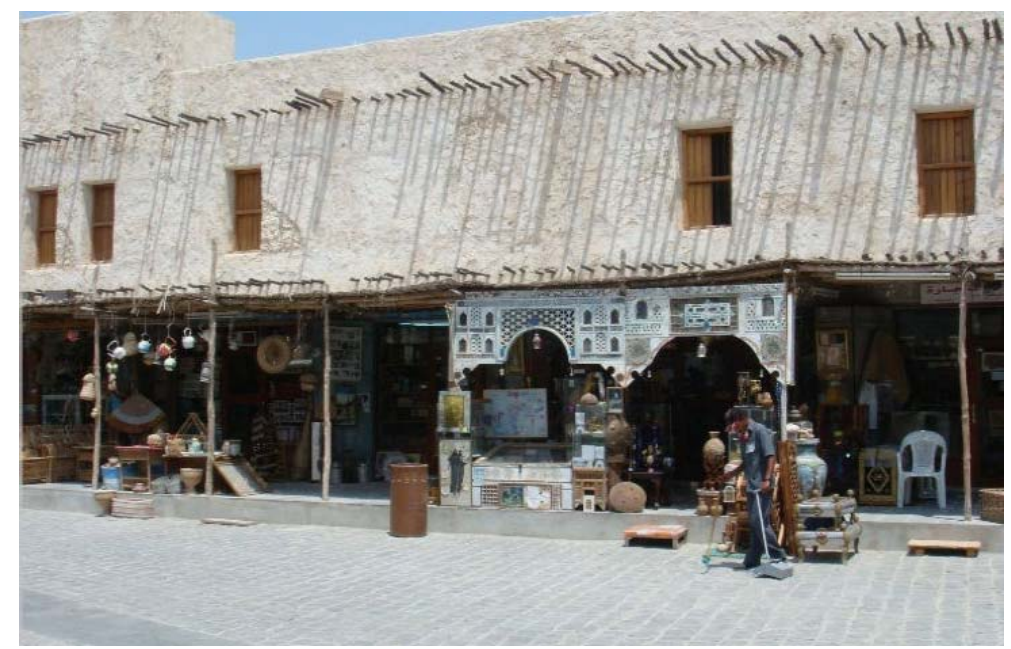

Figure 3. Souk Waqif after restoration/reconstruction in 2004-2005 (photographed in 2009). The restoration used a primitive adobe material to create a wavy textured wall. Such wooden pillars were used in thatching work. This is how traditional modest Qatari houses would have appeared in the past.

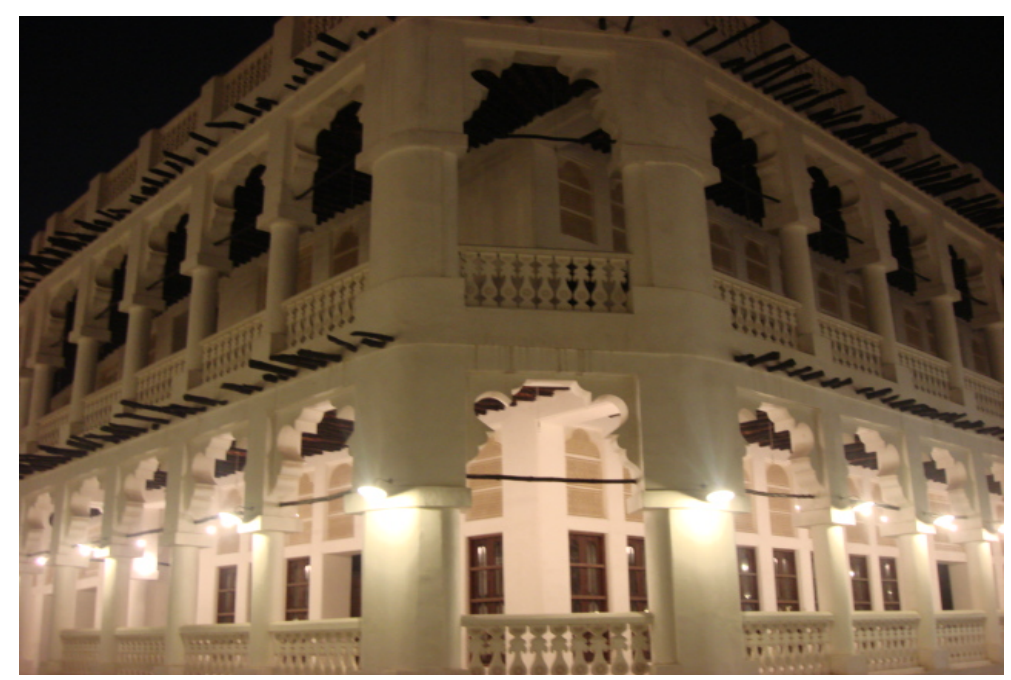

Figure 4. Traditional decorative gypsum and timber work at Souk Waqif. This is a type of costly decorative work that can be found in traditional wealthy family houses (photographed in 2009).

In addition to this, the government developed Souk Waqif Hotel, which is located at the heart of the Souk. This illustrates their intention of turning the Souk into a Qatari landmark and tourist destination.

Jerome de Groot states:

It is clear that history has become one of a set of heritage experiences and referentials. This packaging and commodifying of the past has been critiqued as the "nostalgia mode", where nostalgia without purpose becomes an empty trope within an overly mediated society. Yet simultaneously the importance of the past - the importance of authenticity, empathy, reality, historical truth [...] has never been higher. (Groot, 2009, p. 249)

It is undeniable that Souk Waqif fits directly into this nostalgic mode. In his study Simulacra and Simulation (1994), Jean Baudrillard states that, "when the real is no longer what it was, nostalgia assumes its full meaning” (Baudrillard, 1981, p. 6). Therefore, Baudrillard proposes that the use of simulacra and simulation is usually driven by nostalgia. Thus, we could presume that, in the Qatari case, a simulacrum was used as a "political incantation" to satisfy the nostalgia of the authorities, within which "a large dose of political 
morality" was injected (Baudrillard, 1981, p. 14). Through the reinvention of the souk, the Qatari leaders communicated metaphorically their desire to remove a separation between the real and its artificial resurrection. In this nostalgia within a theatre of the past lie several purposes; each aims to enhance and highlight in its own way Qatari heritage, identity and socio-economic status. David Lowenthal has argued that nostalgia for old and outworn cultural materials has today replaced the longing for development and that, because of the need to satisfy a hunger for the past, nostalgia has a spiritual and physical appeal. He proposes that:

Heritage is not our sole link with the past. History, tradition, memory, myth, and memoir variously join us with what has passed, with forebears, with our earlier selves. But the lure of heritage now outpaces other modes of retrieval. (Lowenthal, 1998, p. 3)

Lowenthal suggests that the interest in the retrieval of history has become a fashion in which "history" has come to mean "heritage". However, unlike history and tradition, heritage can be found everywhere today as we become more engaged with different pasts and eras. "Today [nostalgia] sanctions claims to sites and relics. Stressing traditions that are especially our own, heritage magnifies self-esteem and bolsters communal order" (Lowenthal, 1998, p. 4).

Of universal interest, heritage appears as an image of history, rather than a place or building that possesses a history. Accordingly, the interest in preserving and presenting heritage has become the domain of a specific group of people, those at the top of the social hierarchy. They choose what is worthy of preservation, display and, remembrance. Although not everything can be preserved, there is no doubt that the insistence on the preservation and maintenance of the traditional site is preferable to its replacement by modern buildings. However, what is interesting here is the replication of Souk Waqif and what it presents as Qatar's national heritage.

Walsh suggests that the development of the conservation movement can be located in the nineteenth century in Europe, in the era of industrialising societies. Thus we could compare industrial Europe in the nineteenth century with the reconstruction of Souk Waqif in twenty-first century Qatar. A strong economy has allowed the government to blend direct and indirect policies in the replication of a site in which they could engineer a state of mind to modify public attitudes towards national culture. The government is framed as a responsible protector of national heritage, while simultaneously it takes control of an important part of the population's history and memory that, in its turn, preserves the idea of a "pure” national identity. Replicating the souk in its original form creates an attractive destination for foreign tourists, where they can appreciate and experience “original” Qatari heritage, as it was assumed. The souk is the government's creation of a gigantic simulacrum, which is supposed to provide tourists with a sense of the reality of Qatar in the past. The boom in construction has provoked the need for Qatari people to find an icon where they can demonstrate the strength of the country's identity and show that their heritage has not been undermined. Therefore, the "nation [can look] inwards for a strength through its own identity” (Walsh, 1992, p. 73).

There is no doubt that traditional architecture can provide a symbol of the essence of Qatari heritage, particularly at a time when many designer skyscrapers are spreading along the Doha corniche. It acts to present the leaders' attempts to blend the past with the present, to create a space for history in everyday contemporary life. "Heritage growth thus reflects traumas of loss and change and fears of a menacing future" (Lowenthal, 1998, p. 11). Architectural symbolism is for many a metaphorical representation of the original Qatari identity. This function of the site is apparent in the politicians' insistence on arranging tours for visitors to Souk Waqif 
such as Prince Charles, who toured the souk in February 2007 during his five-day visit to Doha. As seen in Figure 5, he was accompanied by the Emir's daughter, Sheikha Al-Mayassa. The prince rested at its traditional café; its furniture, the way the tea and food are presented and its settings all reflected traditional Qatari customs.

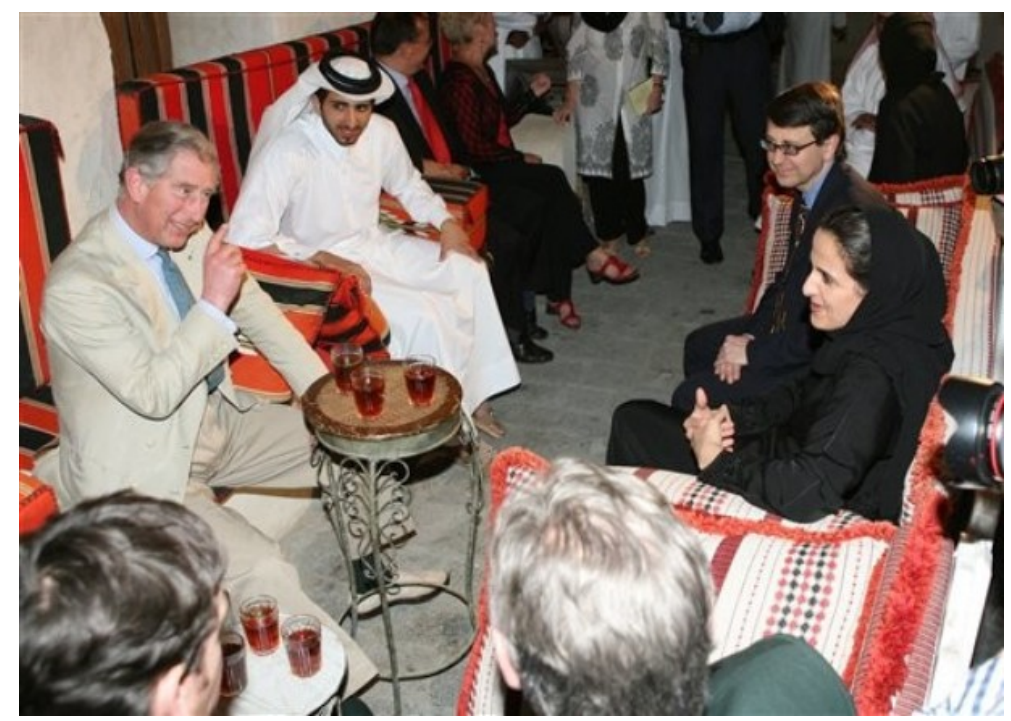

Figure 5. Prince Charles in conversation with Sheikha Al-Mayassa Bin Hamad Al-Thani, the daughter of Qatar's Emir and Chair of Qatar Museums Authority, at a traditional café in Souk Waqif on Friday, 23 February 2007.

The images of this visit in the press demonstrate the ambition to restore the majority of the souk's buildings as traditional Qatari cafés (where men used to gather to enjoy their afternoon leisure time), the traditional Qatari grocery, and shops selling Qatari women's products. Even the Iranian Carriers (the old porters in the souk, a job done by the first immigrants to Qatar) and policemen in traditional uniforms are present.

However, beside these direct and indirect policies, Souk Waqif represents an implicit fear of permanent loss. As Walsh states, "The consumption of certain heritage or museum products serves to enhance the identity and culture capital of individuals and groups" (Walsh, 1992: 127). Souk Waqif's recreation serves to replenish the exhausted national symbols of architecture and heritage. Despite the fact that Souk Waqif's shops were full of traditional local goods before it was destroyed and replicated, the meaning of that heritage was not clear because the traditional objects were accommodated within a modern architecture. During Sheikh Hamad's reign, there has been an expansion in the consumption of heritage. The great number of immigrants in Qatar in relation to the population of indigenous people has without doubt increased the tendency for nostalgia. Nevertheless, the development of heritage as a cultural service did not tend to highlight society's differences. On the contrary it is aimed at presenting a history for Qatar as it continues to operate, despite demographic differences, by promoting the hegemony of identity. "The more people are on the move, the more [leaders] will grasp at a tangible memorial of their collective past” (Lowenthal, 1998, p. 9). We are dealing here with a relationship between heritage and identity, a strategy that the political leaders use to provide a sense of meaning when accommodating Qatari heritage within the market context in Souk Waqif. In contrast, Western designer goods are sold in modern shopping malls.

Today Souk Waqif is located very close to Doha's corniche and its architecture is visible to anyone walking or driving along this popular route. It is a major Qatari tourist destination and an attraction for locals. 
"It is considered the most worthy remaining treasure in Doha city", commented Al-Arab newspaper (Behaper, 2008). Al-Arab further suggests that it is a particular attraction because "both the local and tourist can travel hypothetically to the essence of Qatari heritage and the past via this site” (Behaper:2008).

\section{The Impact of Souk Waqif Restoration in the Qatari Cultural Heritage}

The successful experience of the Souk Waqif project encouraged the Emir to commission another scheme to restore a part of the old coastal city Al-Wakra, where restoration work is finished and eventually provided another traditional tourist site for Qatar. In Figure 6, we can see a development of another simulacrum, in this case a reconstruction of an imagined old city, Al-Wakra. For local inhabitants, in particular, the development of the old city proves that the government has not forgotten or neglected its historical and cultural importance.

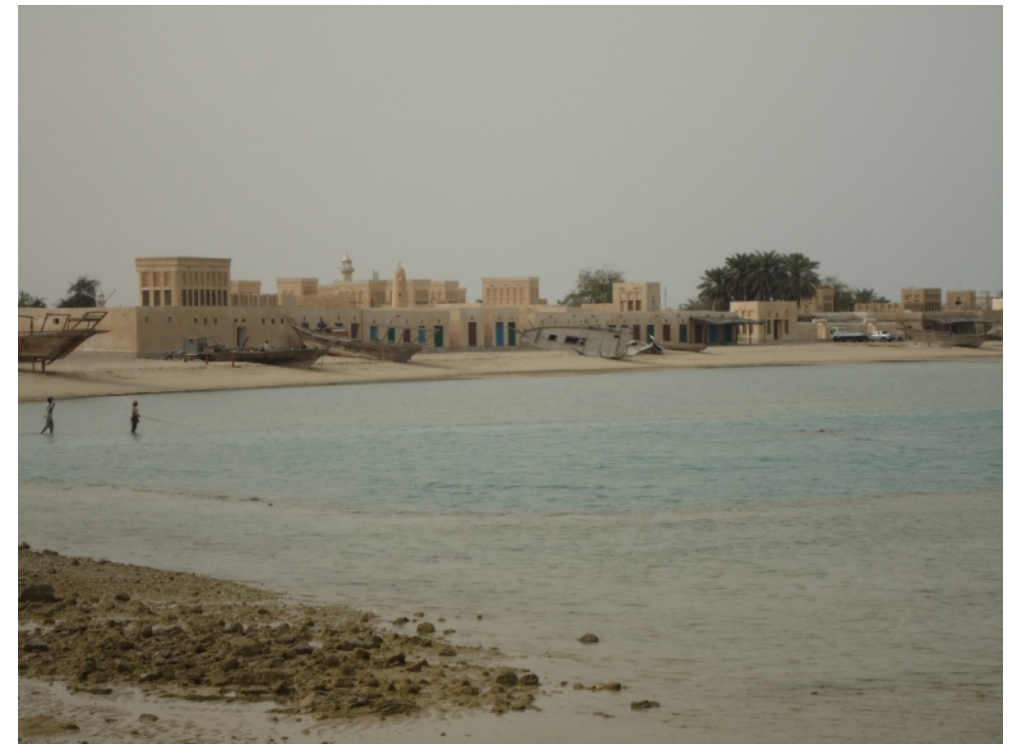

Figure 6. The reconstruction of the old city of Al-Wakra.

The Emir's interest in reconstructing and protecting Qatari architecture has had an impact upon some investors, who have employed Qatari or Islamic characteristics in the design of their skyscrapers to create a post-modern architectural style that says something about Qatar. What is interesting is that the investors' attitudes reflect how they have been influenced by the government's globalisation and modernisation policies, as they are taking the names of historically recognised heritage sites and applying them to new buildings. For example, Barzan Tower (Figure 7) is a design inspired by the historic Qatari castle of Barzan (Figure 8) located to the north east of the city of Umm Sulal Mohammed, 20 kilometres from Doha. Barzan Castle was built in 1910. Its Arabic name means "the prominent place". It is no wonder then that the new skyscraper was named after the original tower. 


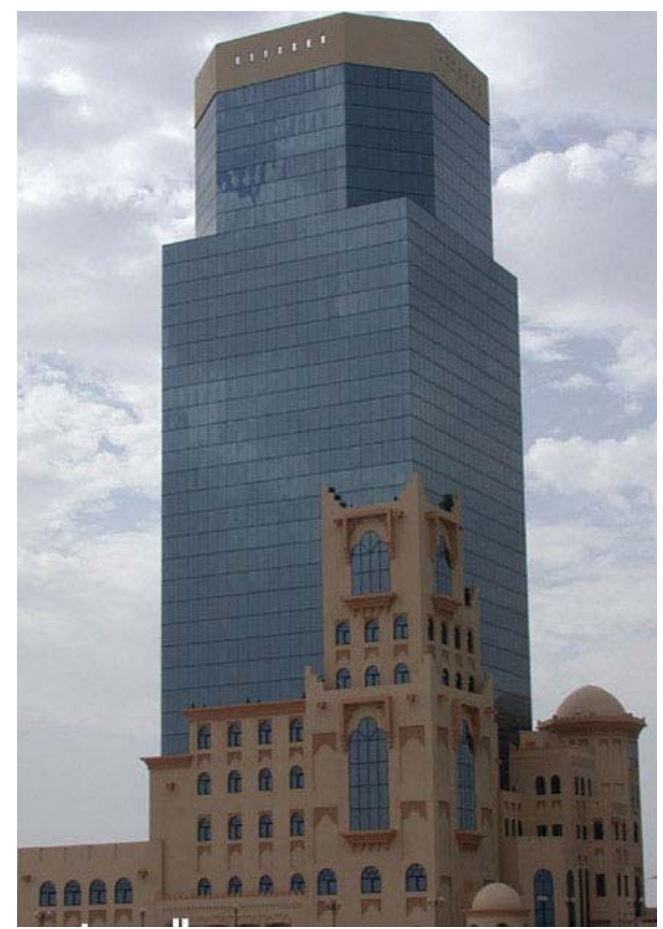

Figure 7. Barzan Tower, which is located among other skyscrapers on Doha’s corniche.

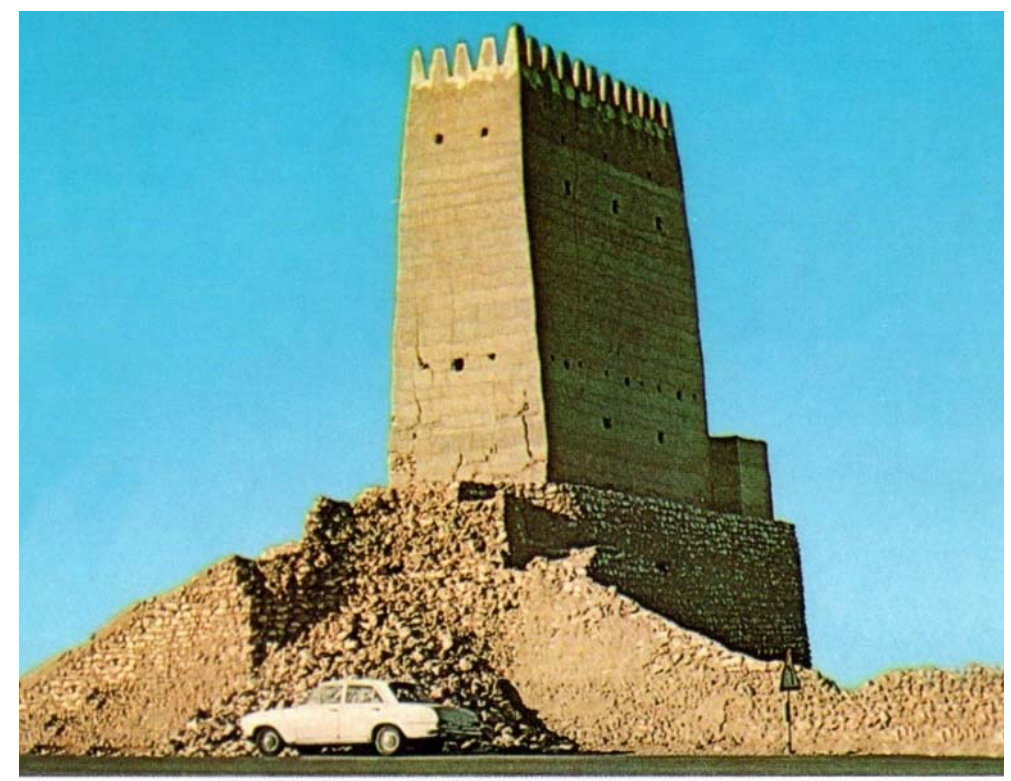

Figure 8. The historic Barzan Castle at Umm Sulal Mohammed in 1968, before restoration.

The echo of the form of Barzan Tower has had positive consequences as further skyscrapers have been built using Qatari architectural inspiration, for example, the new Ministry of Education building (Figure 9); Freej Sharq hotel (Figure 10); and the Fanar Centre that was inspired by the Al-Malwiya minaret of the great Mosque Samara in Iraq 848/49 AD (Figure 11). The latter is inspired by an Islamic element rather than anything specifically Qatari and thus demonstrates the mix of architectural inspiration that we will see in Pei's designs for the Museum of Islamic Art. 


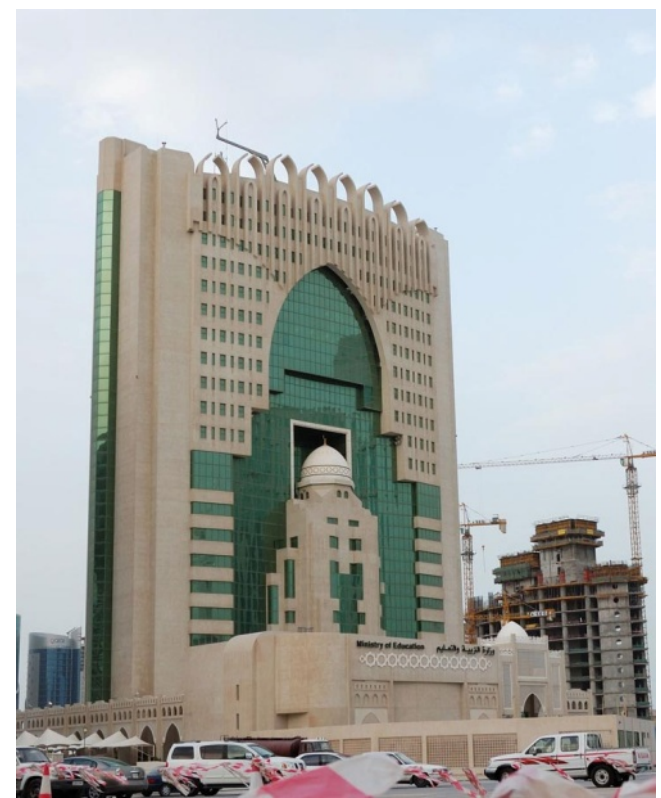

Figure 9. The new building for the Ministry of Education. Islamic inspiration is evident in the dome and the shape of the middle windows.

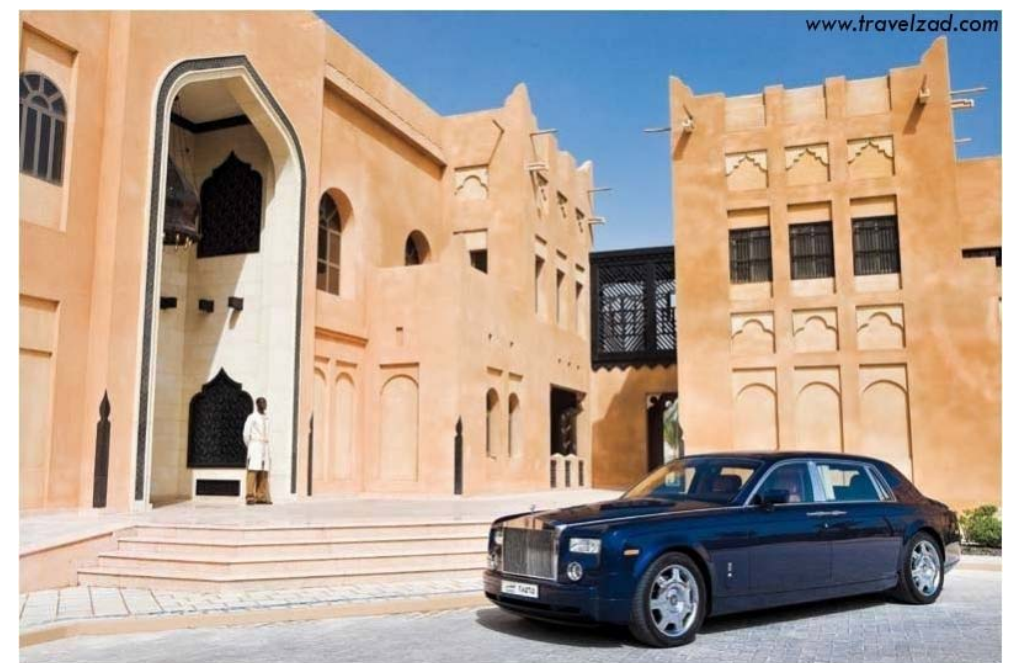

Figure 10. Freej Sharq Hotel, inspired by and named after the traditional word for the suburb in the Qatari language, "Freej”. 


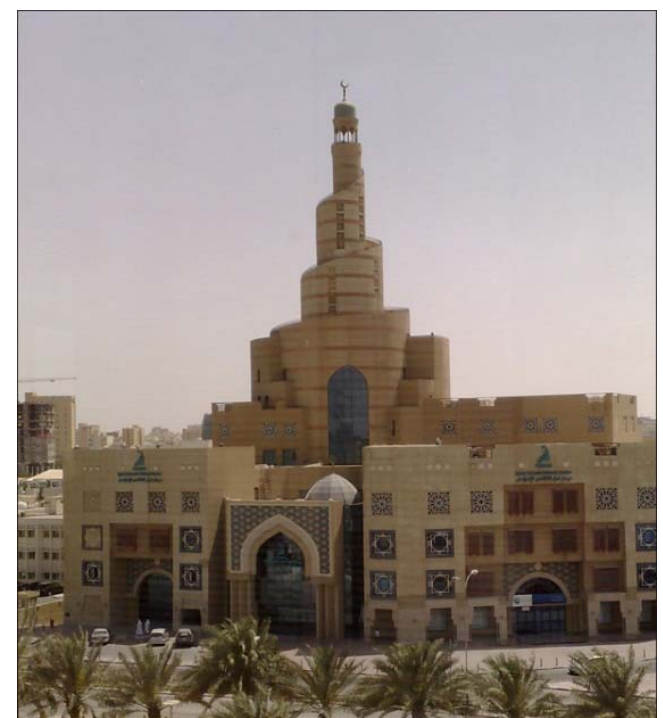

Figure 11. The Fanar Centre, which is clearly visible from both the restored Souk Waqif and the Museum of Islamic Art. This building also uses spotlights at night to create a panorama.

Since 1995, the government has presented itself as a responsible actor, facing the challenge of helping the community to determine its place on the world's map and define its identity, enhancing self-respect while respecting others. As such, it has been vital to develop a specific department to manage this ambition to protect the national architectural inheritance. In April 2007, the Doha Land Company was established under the logo "rediscover the beauty of our heritage" (Doha Land Company, 2011). This department monitors Qatari architecture while demonstrating its capacity to adopt new architectural styles and techniques. In Traditional Architecture in Saudi Arabia: The Central Region States (1990) Marco Albini suggests:

Formal characterization and correspondence to the specific living habits of a country are important factors of the traditional continuity and search for the expression of ethnic identity. On the other hand, stylistic elements and schemes need evolving consistently with our age: while respecting and interpreting tradition, the work should be attuned to today's living standards. (Albini, 1990, p. 7)

Similarly, in contrast to the previous reign, Qatari architecture in Sheikh Hamad's reign occupies a central role in the country's regeneration. However, the choice of style, be that traditional, modern or post-modern, is dictated by a consideration of the country's economic status. This is because the Emir realised that architecture is a very important representation of culture, providing a coherent interaction between architectural design and the surrounding environment. But, is what is presented in Qatar an articulation or a simulacrum and simulation? Mohammed Al-Khulaifi suggests in his study Traditional Qatari Architecture (2000) that architecture is an ideal artwork that refers to and represents the social, psychological and economic status of and to the community. He further suggests in Archaeological Sites, Architecture and Museums in Qatar (2003), that Qatari architecture is distinguished by having been influenced in its designs by original Islamic architecture, which relies on simple forms that carefully consider the country's climate, the sun and the desert. The architecture of Sheraton Hotel Doha, for instance, in Figure 12 was a pioneering architectural symbol in Qatar when it opened during the 1980s. However, it does not represent Islamic or Qatari architectural forms; it was something new that soon became a (hybrid) pyramidal landmark on the shores of Doha Bay. 


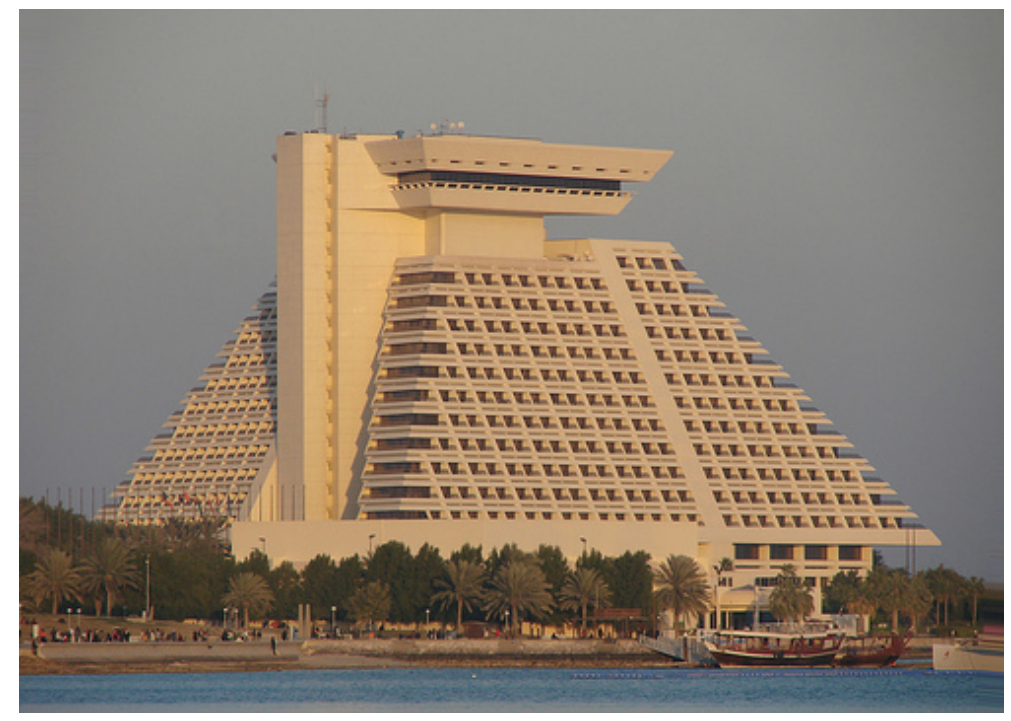

Figure 12. Sheraton Hotel Doha.

Architecture has started to flex its muscles in Qatar, where there is a drive to create an architectural language for the country. There is a dilemma of choice. From the mid 1990s onward the adoption of "synthetic" architecture that blends traditional with contemporary styles to create something new. Perhaps the Emir believes that "the style of architecture is a way of building codified by time" (Crook, 1987, p. 13). Museums, in particular, are viewed as arenas for the powerful display of culture. They do not aim to exclude any evidence of the influence of contemporary life; rather they reflect the changing society in the country by accepting the new. Doha Land Company was launched prior to the announcement of the Emir's 2030 national vision. Through this launch, the Emir (with the Qatar Foundation) consolidated his efforts to protect national architecture with the aim of developing new architectural concepts in building new modern cities. Doha Land Company mainly found inspiration for design from traditional Islamic architecture. The company has four conceptual pillars to support its projects. These are culture, continuance, creativity and enrichment of the environment. Doha Land Company's mission is as follows:

[...] to enhance the social dynamic, the inheritance of heritage and culture and the standard and quality of the daily life, by developing creative projects that offer a contemporary and vibrant life style that harmonizes with its surrounding and allows the individual and the community to improve and flourish.(Al-Arab, 2009)

The establishment of this company raises questions as to whether we are witnessing the creation of a Neo-Qatari architectural style in a manner similar to Neo-Oriental, Neo-Egyptian or Neo-Greek, "styles equally remote in time and place, but not yet equally assimilated or understood" (Crook, 1987, p. 35). This could be possible when we consider that the launch of the company took place at a time when the authorities observed a chronological gap in the development of Qatari architecture. They decided that this gap would prevent Qatari architecture from achieving international distinction. The ambition was therefore to create "a new species of architecture more applicable to [the] country” (Crook, 1987, p. 26). Thus Doha Land Company began its work with pre-determined plans that had been created by the government and were based on researching absent elements and employing them creatively in the new architectural development of Qatar. By developing collaborative projects between foreign and Qatari architects, it is hoped that a good balance can be sustained between native culture and other styles. This action is reminiscent of Lord Lindsay who in 1847 in his History 
of Christian Art called for a new distinguished architectural style for Great Britain, one that would express the human progress of the epoch. Lindsay stated:

This is the problem - England wants a new Architecture, expressive of the epoch, of her Anglican faith and of the human mind as balanced in her development, as heir of the past and trustee for the future [...] We have a right to expect this from the importance of the epoch.(Crook, 1987, p. 100)

Logically then, the Museum of Islamic Art's architecture does not appear as an incongruous form of architecture in Qatar, but as a work of simulacra. Post modernism offers the chance to involve both the past and the present, a key theme of Robert Venturi's definition of the style. During Sheikh Hamad's reign, post-modern architectural style has replaced the modernism of the previous regime. This modernism in its turn had replaced the traditional style of Qatari architecture that followed the country's improvement plans between the mid-1970s and the beginning of the 1990s. Sheikh Hamad's reign is witnessing a shift towards new aesthetic values. The business of evaluating and understanding different architecture styles has begun. Thus different schools of architecture have been combined to create distinct designs, determined by their own goals and circumstances. The story of post-modern architecture in Qatar began with a synthesis of ideas: constructive unity, expressive ornament, vernacular art and didactic art.

Perhaps, it is the Emir's intention and belief that by this method he is balancing Qatari heritage with the most modern creative techniques. In contrast, in Frank Gehry's design of the Abu-Dhabi Guggenheim we see a building that is representative of Gehry's typology (Figure 13). When one looks towards the building, one can identify the architect rather than the location. A visitor to Al-Saydaatisland, the site of Abu-Dhabi Guggenheim Museum, would probably not be able to recognise the cultural setting of the museum.

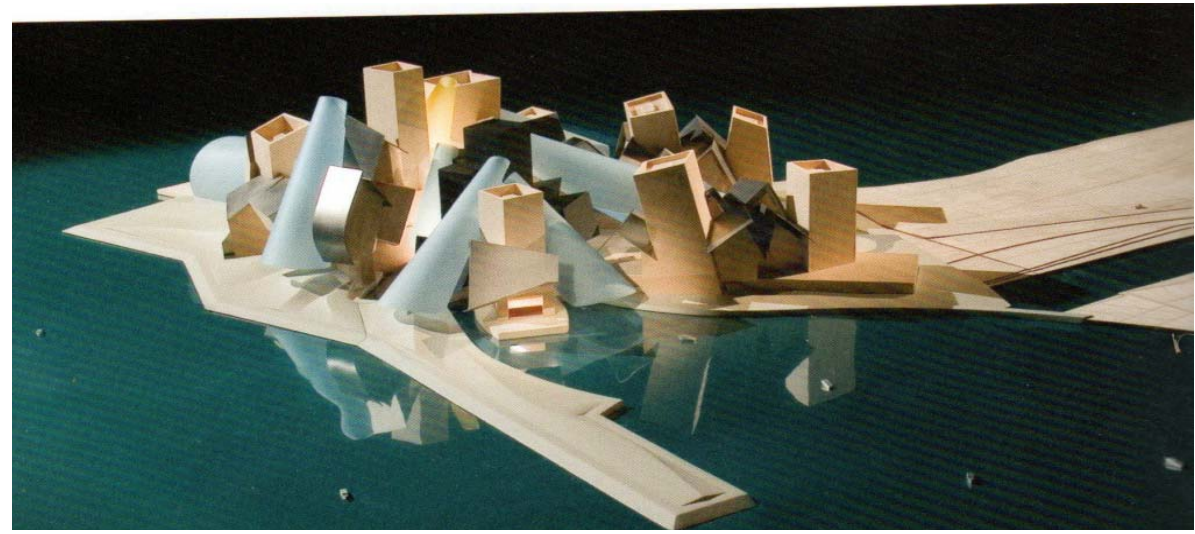

Figure 13. Frank Gehry, proposed design for Abu-Dhabi’s Guggenheim, photographed in July 2006.

In contrast, the MIA's site indicates its own architectural language, which narrates metaphorically for Qatar's visitors the story of Qatar's economic and social development. Both politicians and curators believe that this architecture distinguishes the museum from other museums in the region. It is as if the leaders are sending a message to the public saying, "we have made great social progress in Qatar". The photographer of Figure 14 has enhanced the presentation of the architecture where, after sunset, spotlights crown the cubic forms, focusing illumination on different parts of the building and creating a subtle overall picture. Using the language of Charles Jencks, when writing about the post-modern movement in architecture, the viewer's eye shifts towards the site of the MIA and one inevitably feels the presence of the Qatari fingerprint and character of this unique creation. 


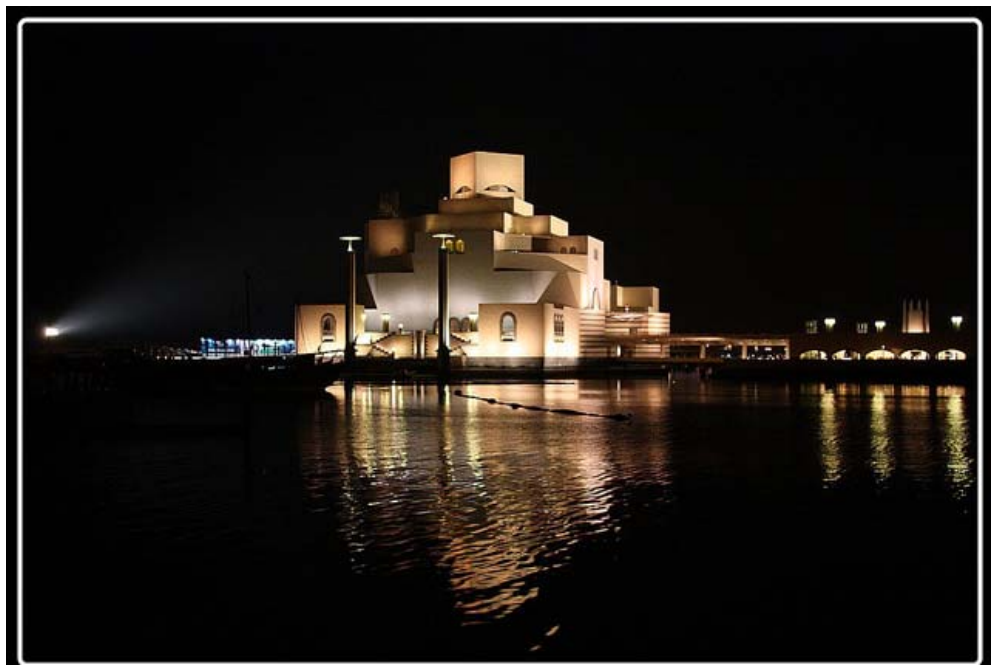

Figure 14. Lighting the Museum of Islamic Art after sunset enhances the impact of the architectural narrative.

\section{Conclusion}

My paper critically traced the narrative of cultural heritage in Qatar that has brought us to the point of the production of new heritage. For instances, the architectural move from tradition to modernism and eventually post-modern style has replaced the modernism. As well as the development of new museum culture. Throughout this paper, it has become more and more evident that the concentration in heritage in Qatar was an integral component in the agenda of the Qatari politicians. They have had, and continue to exert, an overt influence on the narratives of national heritage.

This paper explored how twentieth first-century rulers, such as Sheikh Hamad, succeeded in constructing a national heritage in order to construct an historical archive for the country. I have argued in this paper that, heritage in Qatar has been vital contributor to the political and social development of the country. Throughout this study, it has become clear how often cultural practice has been linked directly to the country's political movement and change. Heritage, cultural and Museum practices, as such, have been consistently included in the political agenda. Perhaps this is because the heritage's own ideological power provides the government with a functional tool through which it can promote its messages in a diplomatic and indirect way.

By the creation of heritage sites, new museum architectures and cultural events, the government aimed to highlight its role, achievements and position to the local population and to stress its interest in preserving the country's heritage. My research has explored an important aspect of heritage practice in Qatar; how cultural policy has been employed to tell the story of national development. This can be seen explicitly in the flurry of different cultural activities, museums and heritage sites established in recent years. These establishments and practices focused on presenting local history and ethnography. Thus, concepts of tradition, heritage, memory, national history and local identities were interpreted for the Qatari communities via such concentration.

\section{References}

“Overview”, Doha Land Company <http://www.dohaland.com/company/overview> [accessed 4 February 2011].

Albini, M. (1990). Traditional architecture in Saudi Arabia: The central region states. Riyadh: Department of Antiquities and Museums, Ministry of Education.

Al-Hassan A. B. (2008). Souk Waqif: A place full of history, Al-Arab

< http://www.alarab.com.qa/admin/pdf/files/1666863892_A26N.pdf> [accessed 26 January 2008]. 
Al-Khulaifi, J. M. (2000). Traditional Qatari Architecture (p. 25). Doha, National Council for Culture, Arts and Heritage.

Al-Kulaifi, J. M. (2000). Qatari traditional architecture (pp. 19-20). Doha: The National Council for Culture, Art and Heritage.

Al-Kulaifi, J. M. (2003). Archaeological Sites-Architectural Heritage-Museums in Qatar (pp. 100-102). Doha, National Council for Culture, Arts and Heritage.

Anderson, G. (1995). The problems of preserving architecture in the urban area in Sharja (pp. 329-337). Sharja: Press Culture Department.

Chakravorty, G. S. (1985). The rani of Sirmur: An essay in reading the archives. History and Theory, 24:3 (October), $247-272$.

Crook, M. J. (1987). The dilemma of style (p. 100). London: The British Museum.

Groot, J. (2009). Consuming history: Historians and heritage in contemporary popular culture (p. 249). London and New York: Routledge.

Hoyau, Ph. (1988). Heritage and the conserver society: The French case. In R. Lumley (Ed.), The museum time machine (pp. 27-35). London and New York: Routledge.

Jean, B. (1981) Simulacra and simulation. Ann Arbor: The University of Michigan Press.

Jencks, Ch. (1985). The modern movement in architecture (pp. 97-107). London: Clays Ltd.

Lowenthal, D. (1998). The heritage crusade and the spoils of history. Cambridge: Cambridge University Press.

Sheikha Al-Mayassa: Qatar will be the centre of the Middle East museums <http://www.qatarfootball.com> [accessed 18 July 2008].

Simpson, G. M. (2001). Making representations: Museums in the post-colonial era (pp. 35-49). London and New York: Routledge.

The Launching of Doha Land Company for Building Development in New Architecture Concept, Al-Arab, Wednesday, 4 March 2009, <http://www.alarab.com.qa/main.php?issueNo=436\&secId=17\&subsec=47> [accessed 4 March 2009].

Venturi, R. (1977). Complexity and Contradiction in Architecture (pp. 16-20). London, The Architecture Press.

Walsh, K. (1992). The Representation of the Past: Museums and heritage in the post-modern world (pp. 11-12). London and New York: Routledge. 